Swiichi Konuma and Ruo Ogawa (2003). "Effcacy of Intrathecal Morphine for analgesia Following Elective Cesarean Section: comparison with Previous Delivery", J Nippon Med Sch 70 (4).

2. Cardoso MM, Carvalho JC, Amaro AR (1998) Small dose of intrathecal morphine combined with systemic diclofenac for posteoperative pain control after dilivery. Anesth Analog: 86: 538-541.

3. Abboud TK, Dror A, Mosaad P, Zhu J, Mantilla M, Swart F (1988), "Mini-dose intrathecal morphine for the relief of post- cesarean section pain: safety, efficacy, and ventilatory responses to carbon dioxide. Anesth Analg 67, pp. $137-41$.

4. Phan Anh Tuấn (2008), "Đánh giá tác dụng của Gây tê tủy sống băng bupivacain kết hợp morphin và bupivacain kết hợp fentanyl trong mổ chi dưới", Luận văn thạc sỹ y học, Học viện Quân y.
5. Trân Đình Tú (2006) "Sự kết hợp bupivacaine (Marcaine heavy 0,5\%) với morphine hydroclorid bằng phương pháp gây tê tuỷ sống để vô cảm trong mổ và giảm đau sau mô lấy thai". Báo cáo khoa hoc.

6. Nguyến Văn Minh và cs (2007) Nghiên cứu tác dụng giảm đau sau mổ của Morphine tủy sống trong mổ lấy thai.

7. Đố Văn Lợi (2007): "Nghiên cứu phối hợp Bupivacain với Morphin hoăc Fentanyl trong gây tê tuỳ sống để mổ lấy thai và giảm đau sau mô", Luận văn thạc sỹ y học. Trường đại học Y Hà Nội.

8. An Thành Công (2011), "Đánh giá tác dung giảm đau dự phòng sau mổ tầng bụng trên bằng phương pháp tiêm morphine tủy sống", Luân văn thạc sỹ y học, Trường Đại học Y Hà Nội.

\title{
NGHIÊN CỨU ỨNG DỤNG PHƯƠNG PHÁP GÂY TÊ NGOÀI MÀNG CỨNG ĐỂ GIẢM ĐAU CHUYỂN DA CHO SẢN PHU SINH THƯỜNG TẠI BỆNH VIỆN SẢN-NHI TỈNH QUẢNG NGÃI
}

\section{TÓM TẮT}

Đắt vấn đề: Hiện nay, phương pháp giảm đau chuyển dạ bằng gây tê ngoài màng cứng được áp dung tại nhiều bệnh viện Phụ sản, đem lại nhiều lợi ích cho sản phụ và làm giảm tỷ lệ sinh mổ. Bệnh viện chúng tôi đang sử dụng phương pháp gây tê ngoài màng cứng bằng Bupivacain phối hợp với Fentanyl để giảm đau trong chuyển da nhưng chưa được đánh giá, chúng tôi muốn xem hiệu quả tác dụng giảm đau của phối hợp hai loại thuốc này. Muc tiếu: Đánh giá hiệu quả giảm đau, các tác dụng k̂̉ông mong muốn và mức độ hài lòng của sản phụ khi lựa chọn phương pháp gây tê ngoài màng cứng trong chuyển dạ sinh thường bằng phối hợp thuốc Bupivacain và Fentanyl. Đối tượng và phướng pháp nghiên cứu: Nghiên cứu cắt ngang mô tả chon sản phụ từ 18-40 tuổi, có chỉ định sinh thường, thuộc nhóm ASA I, II, đồng ý tham gia nghiên cứu và không có chống chỉ đinh gây tê ngoài màng cứng từ tháng 01 đến tháng 10 năm 2020 tại Bệnh viện Sản-Nhi tỉnh Quảng Ngãi. Kết quả: 326 sản phụ, chiều cao trung bình là 159,07 $\pm 7,71 \mathrm{~cm}$ và cân nặng trung bình là $60,04 \pm 7,59 \mathrm{~kg}$. Hiệu quả giảm đau trong chuyển dạ: Thời gian khởi tê trung bình là $5,77 \pm 1,35$ phút. Thay đổi điểm VAS: trước khi gây tê điểm VAS trung bình của sản phu là $7,15 \pm 1,28$, tương ứng mức độ đau nhiều và rất nhiều; sau 5 phút gây tê và trong các giai đoạn còn lại của cuộc chuyển dạ, điểm VAS trung bình đều <4. Tác dụng không mong muốn: Phương pháp chưa ghi nhận

${ }^{1}$ Bệnh viện Sản-Nhi tỉnh Quảng Ngãi

Chịu trách nhiệm chính: Nguyển Đình Tuyến

Email: nguyendinhtuyen889@gmail.com

Ngày nhận bài: 13.11.2020

Ngày phản biên khoa hoc: 6.01.2021

Ngày duyệt bài: 19.01.2021

\section{Nguyễn Đình Tuyến ${ }^{1}$, Nguyễn Tiến Dũng1}

ảnh hưởng đến tim thai trong chuyển dạ; không ảnh hưởng đến tần số tim cũng như thay đổi $\mathrm{SpO}_{2}$, huyết áp của sản phụ. Ghi nhận một số tác dụng không mong muốn nhứng không ảnh hưởng đến tổng trạng sản phu trong cuộc đẻ như: lanh run, tưt huyết áp, nôn, bí tiểu, ngứa, đau đầu. Tỷ lệ sản phụ rất hài lòng là $30,68 \%$. Kết luân: Phương pháp duy trì giảm đau trong các giai đoạn của quá trình chuyển dạ đều rất tốt, thể hiện: trước khi gây tê điểm VAS trung bình đều $>7$, sau khi khởi tê điểm VAS trung bình ở các giai đoạn của chuyển da đều <4. Phương pháp chưa ghi nhẩn ảnh hưởng tới hô hấp của sản phư và tân số tim thai. Tỷ lệ tác dụng không mong muốn ít. Tỷ lệ sản phụ hài lòng cao.

Tư khóa: Gây tê ngoài màng cứng, giảm đau chuyển dạ, Bệnh viện Sản-Nhi tỉnh Quảng Ngãi.

\section{SUMMARY}

\section{RESEARCH ON EPIDURAL ANESTHESIA FOR PAIN RELIEF IN LABOR AT QUANG NGAI HOSPITAL FOR WOMEN AND CHILDREN}

Background: Epidural analgesia is a commonly used method of pain relief in labor in many obstetrics hospitals, brings various benefits and avoids unnecessary cesarean sections. Epidural anesthesia with Bupivacain and Fentanyl has been used during labor in our hospital and not evaluated yet. Objectives: To evaluate the effectiveness of pain relief, adverse effects and maternal satisfaction with epidural analgesia during labor. Methods: This was a cross-sectional study on pregnant women reporting from January to October 2020 at Quang Ngai Hospital for Women and Children. The woman aged 18-40 years, classified as American Society of Anesthesiologists score I and II who requested epidural analgesia in active labor were taken for this 
study. Women with any contraindications to epidural techniques were excluded. Results: Out of 326 pregnant women, the figure for mean weight and height was $60,04 \pm 7,59 \mathrm{~kg}$ and $159,07 \pm 7,71 \mathrm{~cm}$ respectively. The efficacy of analgesia: the mean time of onset of analgesia was 5,77 $\pm 1,35$ minutes. Visual analog scale: Before epidural injection, VAS score was $7,15 \pm 1,28$. After 5 minutes of epidural anesthesia and in subsequent evaluation periods, the VAS score decreased to under 4. Maternal adverse effects: We found no significant alterations with regard to maternal $\mathrm{SpO}_{2}$ values, pulse, blood pressure and fetal heart rate. There were several clinical adverse effects such as hypotension, headache, shivering, nausea and vomiting, urinary retention. $30,68 \%$ of patients reported it as a very good experience and satisfied with the procedure. Conclusion: Epidural anesthesia is an efficient way of pain relief during labor and delivery: Before epidural injection, VAS score was more than 7. In subsequent evaluation periods, the VAS score was under 4 . There were no significant alterations in terms of fetal heart rate and respiratory rate of the pregnants. Adverse effects and complications were not noted.

Keywords: epidural analgesia, pain relief in labor, Quang Ngai Hospital for Women and Children.

\section{I. ĐĂT VẤN ĐỀ}

Có nhiều phương pháp giảm đau trong chuyển dạ như gây tê ngoài màng cứng (GTNMC), gây tê tủy sống, gây tê vùng, gây mê tĩnh mach... Trong đó phương pháp GTNMC được đánh giá là có nhiêu ưu điểm như giúp giảm đau hiệu quả, tránh mất sức cho sản phụ, ít ảnh hưởng đến thai nhi. Tại Quảng Ngãi chưa có nghiên cứu nào về GTNMC được thực hiện và Bênh viên Sản-Nhi tỉnh chỉ mới bước đầu áp dụng kỹ thuật này trong khi nhu cầu giảm đau trong chuyển dạ của sản phụ ngày càng cao. Muc tiêu nghiên cứu:

1. Đánh giá hiệu quả giảm đau của phương pháp gây tê ngoài màng cứng trong chuyển dạ cho sản phu sinh thường bằng thuốc Bupivacain và Fentanyi.

2. Ghi nhận các tác dụng không mong muốn của phương pháp gây tê ngoài màng cứng giảm đau trong chuyển dạ.

\section{II. ĐỐI TƯƠ'NG VÀ PHƯƠNG PHÁP NGHIÊN CỨU}

Thiết kế nghiên cứu: Mô tả cắt ngang.

Đối tượng nghiên cứu: sản phụ tuổi từ 1840, chỉ định sinh thường.

\section{Tiêu chuẩn chọn bệnh:}

- Tình trạng sức khỏe ASA I hoặc II; Có chỉ định GTNMC.

+ Tuổi thai đủ tháng, phát triển bình thường.

+ Một thai, không có bất cân xứng khung chậu-thai nhi.

+ Ngôi chỏm, tim thai bình thường, cổ tử cung (CTC) mở 3-5cm; Bánh rau, dây rau, ối bình thường.

+ Không có tiền sử phẫu thuật lấy thai hoặc bóc u xơ tử cung.

Cõ̃ mẫu

$$
n \geq \frac{Z_{1-\alpha / 2}^{2} P(1-P)}{d^{2}}
$$

- $\mathrm{P}=94,4 \%$ [3]; $\mathrm{Z}_{(1-\mathrm{a} / 2)=1,96 ;}$ d: độ chính xác tuyệt đối $=2,5 \% ; n=326$.

Chọn sản phụ trong phiên trực của tác giả, ngoại trừ lúc phòng mổ đông bệnh có bệnh mổ trùng với bệnh GTNMC, chọn cho đến khi đủ 326 sản phụ thì dừng.

Địa điểm và thời gian nghiên cứu: Bệnh viện Sản-Nhi tỉnh Quảng Ngãi từ tháng 01 đển tháng 10 năm 2020.

Xử lý số liệu: phần mềm SPSS 20.0.

\section{KẾT QUẢ NGHIÊN CứU}

\section{1. Đặc điểm chung của sản phụ}

326 sản phụ, chiêu cao trung bình là $159,07 \pm 7,71 \mathrm{~cm}$ và cân nặng trung bình là $60,04 \pm 7,59 \mathrm{~kg}$.

Bảng 1. Số lân mang thai và vị trí GTNMC

\begin{tabular}{|c|c|c|c|}
\hline \multicolumn{2}{|c|}{ Đặc điểm } & $\begin{array}{c}\text { Số lướng } \\
\text { (n=326) }\end{array}$ & $\begin{array}{c}\text { Tỷ lệ } \\
\text { \% }\end{array}$ \\
\hline Mang & Lân I & 218 & 66,9 \\
\cline { 2 - 4 } thai & Lân II trở lên & 108 & 33,1 \\
\hline Vị trí & L3-4 & 291 & 89,3 \\
\cline { 2 - 4 } GTNMC & L2-3 & 35 & 10,7 \\
\hline
\end{tabular}

Nhận xét: GTNMC phần lớn là sản phụ mang thai lần đầu. Gần 90\% sản phụ được GTNMC tại vị trí L3-4.

2. Hiệu quả giảm đau trong chuyển dạ bằng phương pháp GTNMC

Bảng 2. Một số đặc điểm liên quan đến giảm đau chuyến dạ

\begin{tabular}{|c|c|c|}
\hline Đặc điểm & $\begin{array}{c}\text { Trung } \\
\text { bình } \\
\text { Đố lệ̂́ch } \\
\text { chuẩn }\end{array}$ & $\begin{array}{c}\text { Thấp } \\
\text { nhất- } \\
\text { Cao } \\
\text { nhất }\end{array}$ \\
\hline $\begin{array}{c}\text { Từ da đến khoang NMC } \\
\text { (cm) }\end{array}$ & $4,04 \pm 0,43$ & $\begin{array}{c}3,5- \\
5,0\end{array}$ \\
\hline $\begin{array}{c}\text { Độ dài catheter lưu } \\
\text { trong khoang NMC (cm) }\end{array}$ & $4,01 \pm 0,59$ & $\begin{array}{c}2,5- \\
5,0\end{array}$ \\
\hline $\begin{array}{c}\text { Độ mở CTC khi gây tê } \\
\text { (cm) }\end{array}$ & $3,67 \pm 0,70$ & $3-5$ \\
\hline Thời gian khởi tê (phút) & $5,77 \pm 1,35$ & $4-8$ \\
\hline
\end{tabular}

Nhận xét: Khoảng cách trung bình từ da đến khoang NMC là 4,04 $\pm 0,43 \mathrm{~cm}$. Độ mở CTC của sản phụ nhỏ nhất $3 \mathrm{~cm}$, rộng nhất $5 \mathrm{~cm}$.

Bảng 3. Điểm đau VAS

\begin{tabular}{|c|c|c|}
\hline Thời điểm & $\begin{array}{c}\text { Trung } \\
\text { bình } \pm \\
\text { Độ lệch }\end{array}$ & $\begin{array}{c}\text { Thấp } \\
\text { nhất } \\
\text {-Cao }\end{array}$ \\
\hline
\end{tabular}




\begin{tabular}{|c|c|c|}
\hline & chuấn & nhất \\
\hline Trước khi GTNMC & $7,15 \pm 1,28$ & $5-9$ \\
\hline Sau 1 phút & $4,21 \pm 1,37$ & $3-7$ \\
\hline Sau tê 5 phút & $3,94 \pm 1,06$ & $2-6$ \\
\hline Sau tê 10 phút & $2,18 \pm 0,82$ & $1-4$ \\
\hline Sau tê 15 phút & $1,81 \pm 0,94$ & $0-3$ \\
\hline Sau tê 20 phút & $1,27 \pm 0,69$ & $0-3$ \\
\hline CTC mở hết & $3,51 \pm 1,95$ & $1-6$ \\
\hline Thời điếm số thai & $3,87 \pm 1,98$ & $1-7$ \\
\hline $\begin{array}{c}\text { Thời điếm khâu tâng } \\
\text { sinh môn }\end{array}$ & $3,89 \pm 1,92$ & $1-7$ \\
\hline
\end{tabular}

Nhân xét: Trước gây tê, điểm VAS từ 5-9. Sau gây tê tại các thời điểm 10, 15, 20 phút, điểm VAS <4 điểm. Khi CTC mở hết, thời điểm sổ thai, điểm VAS trung bình tăng lên.

3. Tác dụng không mong muốn của phương pháp GTNMC giảm đau chuyển dạ

Bảng 4. Thay đôỉ trên tré sơ sinh

\begin{tabular}{|c|c|c|}
\hline $\begin{array}{c}\text { Thay đối chỉ số } \\
\text { Apgar }\end{array}$ & $\begin{array}{l}\text { Trung bình士 } \\
\text { Đô lệch chuẩn }\end{array}$ & $\begin{array}{l}\text { Thấp nhất } \\
\text {-Cao nhất }\end{array}$ \\
\hline $\begin{array}{c}\text { Cân nặng lúc sinh } \\
\text { (gram) }\end{array}$ & $3000 \pm 325$ & $2500-3600$ \\
\hline Apgar phút thứ 1 & $7,62 \pm 0,50$ & $5-8$ \\
\hline Apgar phút thứ 5 & $8,98 \pm 0,18$ & $8-10$ \\
\hline
\end{tabular}

Nhânn xét: Chỉ số Apgar sau 1 phút và 5 phút lần lượt là 7,62 0,50 và $8,98 \pm 0,18$.

Bảng 5. Thay đổi nhịp tim sản phy trong chuyến dạ (nhịp/phút)

\begin{tabular}{|c|c|c|}
\hline Thời điểm & $\begin{array}{c}\text { Trung } \\
\text { bình士 } \\
\text { Độ lệch } \\
\text { chuẩn }\end{array}$ & $\begin{array}{l}\text { Thấp } \\
\text { nhất } \\
\text {-Cao } \\
\text { nhất }\end{array}$ \\
\hline Trước khi GTNMC & $88,30 \pm 7,84$ & 74-99 \\
\hline Sau 1 phút & $85,27 \pm 10,51$ & $60-100$ \\
\hline Sau tê 5 phút & $85,21 \pm 11,45$ & $60-98$ \\
\hline Sau tê 10 phút & $84,83 \pm 11,41$ & $64-98$ \\
\hline Sau tê 15 phút & $83,63 \pm 11,34$ & $65-98$ \\
\hline Sau tê 20 phút & $83,63 \pm 12,21$ & $59-98$ \\
\hline CTC mở hết & $84,75 \pm 10,49$ & $65-99$ \\
\hline Thời điểm sổ thai & $84,83 \pm 9,47$ & $69-99$ \\
\hline $\begin{array}{l}\text { Thời điếm khâu tâng sinh } \\
\text { môn }\end{array}$ & $86,75 \pm 10,49$ & $70-99$ \\
\hline
\end{tabular}

Nhận xét: Không có sự thay đổi nhịp tim đáng kể tại các thời điểm trong chuyển dạ.

Bảng 6. Thay đổi HATB của sán phỵ trong chuyển dạ ( $\mathrm{mmHg}$ )

\begin{tabular}{|c|c|c|}
\hline Thời điểm & $\begin{array}{c}\text { Trung } \\
\text { bình士 } \\
\text { Độ lệch } \\
\text { chuẩn }\end{array}$ & $\begin{array}{c}\text { Thấp } \\
\text { nhất } \\
- \text { Cao } \\
\text { nhất }\end{array}$ \\
\hline Trước khi tê NMC & $93,16 \pm 9,93$ & $79-108$ \\
\hline Sau 1 phút & $92,58 \pm 10,19$ & $79-108$ \\
\hline Sau tê 5 phút & $91,15 \pm 10,01$ & $79-112$ \\
\hline
\end{tabular}

\begin{tabular}{|c|c|c|}
\hline Sau tê 10 phút & $90,75 \pm 10,96$ & $73-108$ \\
\hline Sau tê 15 phút & $89,54 \pm 11,82$ & $72-107$ \\
\hline Sau tê 20 phút & $89,23 \pm 10,64$ & $75-103$ \\
\hline CTC mơ hết & $93,44 \pm 8,27$ & $67-103$ \\
\hline Thời điếm số thai & $94,06 \pm 7,24$ & $76-103$ \\
\hline $\begin{array}{c}\text { Thời điếm khâu tâng sinh } \\
\text { môn }\end{array}$ & $95,01 \pm 11,82$ & $70-107$ \\
\hline
\end{tabular}

Nhận xét: HATB có thay đổi nhẹ nhưng trở lại bình thường.

Bảng 7. Thay đôi $\mathrm{SpO}_{2}$ của sản phy trong chuyển dạ (\%)

\begin{tabular}{|c|c|c|}
\hline Thời điểm & $\begin{array}{c}\text { Trung bình } \\
\text { Độ lệ̂ch } \\
\text { chuẩn }\end{array}$ & $\begin{array}{c}\text { Thấp nhất } \\
\text {-Cao nhất }\end{array}$ \\
\hline Trước khi tê NMC & $97,94 \pm 1,32$ & $96-100$ \\
\hline Sau 1 phút & $97,91 \pm 1,24$ & $96-100$ \\
\hline Sau tê 5 phút & $97,69 \pm 1,19$ & $96-100$ \\
\hline Sau tê 10 phút & $97,46 \pm 1,18$ & $96-99$ \\
\hline Sau tê 15 phút & $97,75 \pm 1,15$ & $96-99$ \\
\hline Sau tê 20 phút & $98,12 \pm 1,23$ & $96-99$ \\
\hline CTC mở hết & $98,03 \pm 1,21$ & $96-99$ \\
\hline Thời điểm số thai & $98,05 \pm 1,20$ & $96-100$ \\
\hline $\begin{array}{c}\text { Thời điểm khâu } \\
\text { tâng sinh môn }\end{array}$ & $97,20 \pm 1,13$ & $96-99$ \\
\hline
\end{tabular}

Nhânn xét: Độ bão hòa $\mathrm{SpO}_{2}$ ít thay đổi trong quá trình chuyển dạ.

Bảng 8. Thay đổi tân số tim thai trong chuyển dạ (lân/phút)

\begin{tabular}{|c|c|c|}
\hline Thời điểm & $\begin{array}{c}\text { Trung bình } \\
\text { Đô̂ lệch } \\
\text { chuẩn }\end{array}$ & $\begin{array}{c}\text { Thấp nhất } \\
\text {-Cao nhất }\end{array}$ \\
\hline Trước khi tê NMC & $139,37 \pm 9,91$ & $127-154$ \\
\hline Sau 1 phút & $141,18 \pm 8,84$ & $125-159$ \\
\hline Sau tê 5 phút & $141,62 \pm 10,15$ & $125-159$ \\
\hline Sau tê 10 phút & $140,44 \pm 10,92$ & $123-159$ \\
\hline Sau tê 15 phút & $141,78 \pm 10,69$ & $125-161$ \\
\hline Sau tê 20 phút & $142,04 \pm 9,93$ & $129-163$ \\
\hline CTC mơ hết & $140,66 \pm 10,19$ & $125-156$ \\
\hline
\end{tabular}

Nhânn xét: Nhịp tim thai tại các thời điểm chuyển dạ đều trong giới hạn bình thường.

Bảng 9. Thời gian chuyển dạ tư giai đoạn IB đến khi sồ thai

\begin{tabular}{|c|c|c|}
\hline $\begin{array}{c}\text { Giai đoan IB đến } \\
\text { số thai }\end{array}$ & $\begin{array}{c}\text { Trung bình } \\
\text { Độ lệch } \\
\text { chuấn }\end{array}$ & $\begin{array}{c}\text { Thấp nhất } \\
\text {-Cao nhất }\end{array}$ \\
\hline $\begin{array}{c}\text { Thời gian chuyến dạ } \\
\text { (phút) }\end{array}$ & $300 \pm 35$ & $200-400$ \\
\hline
\end{tabular}

Nhân xét: Thời gian chuyển dạ trung bình của sản phụ là $300 \pm 35$ phút.

Bảng 10. Các tác dụng không mong muôn

\begin{tabular}{|c|c|c|}
\hline $\begin{array}{c}\text { Tác dụng không } \\
\text { mong muốn }\end{array}$ & $\begin{array}{c}\text { Tân số } \\
(\mathbf{2 3 / 3 2 6 )}\end{array}$ & $\begin{array}{c}\text { Tỷ lệ } \\
\text { \% }\end{array}$ \\
\hline Tụt huyết áp & 5 & 1,5 \\
\hline
\end{tabular}




\begin{tabular}{|c|c|c|}
\hline Nôn & 3 & 0,9 \\
\hline Ngứa & 2 & 0,6 \\
\hline Lạnh run & 10 & 3,06 \\
\hline Bí tiếu & 2 & 0,6 \\
\hline Đau đâu & 1 & 0,3 \\
\hline
\end{tabular}

Nhận xét: lạnh run chiếm tỷ lệ cao nhất 3,06\%; tụt HA 1,5\%. Các tác dụng không mong muốn như đau đầu, lạnh run, bí tiểu, nôn chiếm tỷ lệ thấp hơn.

Bảng 11. Mức độ hài lòng của SP

\begin{tabular}{|c|c|c|}
\hline $\begin{array}{c}\text { Sự hài lòng của } \\
\text { SP }\end{array}$ & $\begin{array}{c}\text { Số lượng } \\
\text { (n=326) }\end{array}$ & Tỷ lệ \% \\
\hline Rất hài lòng & 100 & 30,68 \\
\hline Hài lòng & 218 & 66,87 \\
\hline Không hài lòng & 8 & 2,45 \\
\hline Rất khống hài lòng & 0 & 0 \\
\hline Tống cộng & $\mathbf{3 2 6}$ & $\mathbf{1 0 0 , 0}$ \\
\hline
\end{tabular}

Nhận xét: Tỷ lệ sản phụ rất hài lòng 30,68\%; 2,45\% không hài lòng.

\section{BÀN LUÂN}

Đăc điểm chung của sản phu. Đa số SP nằm trong độ tuổi sinh đẻ, từ 18-40 tuổi. Chiều cao và cân nặng trung bình của sản phụ lần lượt là $159,07 \pm 7,7 \mathrm{~cm}$ và $60,04 \pm 7,59 \mathrm{~kg}$.Cân nặng ảnh hưởng đến liều lượng thuốc tê trong GTNMC.

Nghiên cứu của chúng tôi, tỷ lệ sản phụ mang thai lẫn một là 66,9\%. Theo Đố Văn Lợi [2] và Nguyễn Văn Chinh [1], tỷ lệ mang thai lần mốt lần lướt là $76,3 \%$ và $62,4 \%$. Nguyên nhân có thể là do sản phụ sinh con lần đầu thường đầu tư hơn về lân chuyển dạ của mình nên lựa chọn giảm đau trong chuyển dạ. Hơn nữa, có thể do thời gian chuyển da của các trường hợp sản phụ sinh con lần đầu thường kéo dài hơn so với mang thai lần 2 trở lên và mức độ đau cũng nhiều hơn nên nhiều sản phụ sinh con lần đầu yêu cầu được làm giảm đau hơn.

\section{Hiệu quả giảm đau}

Vị trí GTNMC: Trong nghiên cứu này, vị trí gây tê tại L3-4 chiếm 89,3\%. Về mặt giải phẫu khe liên đốt $L 2-3$ và $L 3-4$ có kích thước lớn nhất nên dễ thực hiện thủ thuật, tránh các tai biến về kỹ thuật, đồng thời cần đảm bảo phong bế cảm giác đau trải dài từ T10-S4, vì vậy chúng tôi ưu tiên gây tê L3-4, nếu thất bại chuyển L2-3. Giảm đau NMC là phương pháp duy nhất cung cấp giảm đau hoàn toàn cho cả hai giai đoạn do thuốc lan tỏa về hai phía đầu cùng T10-L1 và S2-S4.

Khoảng cách từ da đến khoang NMC: Nghiên cứu chúng tôi, khoảng cách từ da đến khoang $\mathrm{NMC}$ là 4,04 $\pm 0,43 \mathrm{~cm}$. Kết quả này tương đương nghiên cứu Nguyễn Văn Chinh [1] $(4,03 \pm 0,36$ $\mathrm{cm})$. Khoảng cách này đảm bảo thuốc tê lan tỏa về phía hai đầu và cùng T10-L1 và S2-S4 sẽ có hiệu quả giảm đau rõ rệt. Nhủng phải hết sức thận trọng để tránh chọc thủng màng cứng và gây ra các tai biến kỹ thuật nguy hiểm khác.

Độ mở CTC: CTC mở 3-5 cm, tương ứng với đau nhiều và đau rất nhiều (VAS $>4$ ). Độ mở CTC trung bình là $3,67 \pm 0,7 \mathrm{~cm}$. Kết quả tương tự nghiên cứu của Phùng Quang Thủy [4] và Patkar [8] với độ mở CTC tại thời điểm gây tê lần lượt là $3,97 \pm 0,69$ và $2,57 \pm 1,44 \mathrm{~cm}$.

Thời gian khởi tê: Kết quả của chúng tôi, thời gian khởi tê trung bình là $5,77 \pm 1,35$ phút. Theo Nguyễn Văn Chinh [1] thời gian khởi tê là $16,44 \pm 0,43$ phút dài hơn chúng tôi; có thể do liều lượng thuốc tê ở liều bolus đâu tiên trong nghiên cứu của chúng tôi cao hơn.

Tác dụng không mong muốn

Thay đợi tần số tim thai: Đau trong chuyển dạ gây tăng nồng độ catecholamin trong huyết tương có thể gây tăng nhịp tim, cung lượng tim và sức cản mạch ngoại vi. Nghiên cứu chúng tôi trước gây tê, nhịp tim trung bình của sản phụ là: $88,30 \pm 7,84$ nhịp/phút. Sau gây tê, tần số tim của sản phu có giảm tai các thời điểm của quá trình chuyển dạ, góp phần làm ổn định nhịp tim của sản phụ.

Huyết áp trung binh: nghiên cứu cho thấy HATB trước gây tê là $93,16 \pm 9,93 \mathrm{mmHg}$, sau gây tê, HATB giảm, sau đó trở lại bình thường. Theo Nguyễn Văn Chinh [1] sau gây tê các thời điểm 20 phút và sau gây tê 1 giờ, HATB thay đổi nhưng không giảm.

Độ bão hòa $\mathrm{SpO}_{2}$ trung binh: Nghiên cứu cho thây trước khi gây tê độ bão hòa oxy trung bình là $97,94 \pm 1,32 \%$. Sau khi GTNMC độ bão hòa oxy trung bình tăng lên. Sau khi gây tê sản phụ đã bớt đau nên có thể thở sâu, nhịp nhàng và đều đặn theo hướng dẫn của nhân viên y tế, do vậy thông khí có hiệu quả tốt hơn.

Trước khi gây tê điểm VAS trung bình là $7,15 \pm 1,28$ tương ứng với mức độ đau vừa và đau rất nhiều. Sau gây tê 5 phút, điểm VAS đều $<4$. Giảm đau trong chuyển dạ thường bắt đâu thực hiện khi CTC mở từ 3-5 cm, cơn go TC mạnh, vì vậy trước khi gây tê, điểm VAS thường rất cao. Sau gây tê, thuốc tê phát huy tác dụng thì điểm đau giảm mạnh, sản phụ đau ít hoăc không đau nên thư giãn nghỉ ngơi, giữ sức rặ̆n đẻ hiệu quả hơn. Theo Esra K [6], điểm VẢS trước gây tê là $8,5 \pm 0,5$; giai đoạn sổ thai là $0,6 \pm 0,7$; giai đoạn may tầng sinh môn là $0,8 \pm 0,9$ thấp hơn rất nhiều so với nghiên cứu chúng tôi.

Tần số tim thai: Trong nghiên cứu này, tần số 
tim thai trước khi gây tê và trong các giai đoạn chuyển dạ đều trong giới hạn bình thường (trung

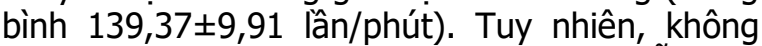
có trường hợp nào thai bị suy. Theo Nguyễn Văn Chinh[1], tim thai thay đổi có ý nghĩa trong khoảng 30 phút đầu sau chích thuốc tê và thuốc giảm đau nhưng đa số tự hồi phục.

Chi số Apgar: Nghiển cứu cho thây chỉ số Apgar sau 1 phút là $7,62 \pm 0,50$; sau 5 phút $8,98 \pm 0,18$. Theo Phùng Quang Thủy [4], chỉ số Apgar sau một phút và 5 phút không có dưới 7 điểm. Giảm đau chuyển dạ không có thay đổi chỉ số Apgar của trẻ, cần khuyến khích nhiều hơn trong giảm đau chuyển dạ bằng phương pháp GTNMC.

Thời gian chuyển da từ giai đoạn IB đến khi sổ thai: Thời gian chuyển dạ giai đoạn này trung bình $300 \pm 35$ phút. Một nghiên cứu khác chỉ ra rằng GTNMC dùng thuốc Bupivacain kết hợp Fentanyl chống co thắt làm dãn $\mathrm{CTC}$, mở nhanh hơn vì vậy phối hợp Oxytocin sẽ sổ thai nhanh hơn, rút ngắn thời gian chuyển dạ.

\section{Các tác dung không mong muốn}

Trong nghiên cứu của chúng tôi, tác dụng không mong muốn chiếm tỷ lệ $7 \%$.

- Lanh run: chiếm 3,06\%, các sản phụ được sưởi ấm, sau đó ổn định. Theo Chora I [5] nhóm dùng Bupivacain kết hợp với Fentanyl ghi nhận 1/10 trường hợp lạnh run.

- Tụt HA: chiếm 1,5\%, chúng tôi nâng $\mathrm{HA}$ bằng truyền dịch và Ephedrine, sản phụ ổn định, các trường hợp khác có dao đông nhưng ồn định. Nghiên cứu Nguyễn Văn Chinh [1], tụt HA chiếm 2,6\%.

- Nôn và buồn nôn: gặp 3 sản phụ chiếm 0,9\%. Sau khi điều trị chống nôn bởi Metoclopramide các sản phụ đỡ nôn và ổn định. Kết quả này thấp hơn nghiên cứu của Phùng Quang Thủy [4] $(8,1 \%)$ và Chora I [5] (2/10 SP).

- Bí tiểu: sau sinh chiếm tỷ lê $0,6 \%$, chúng tôi chỉ chườm ấm rồi sau đó tự đi tiểu không phải đăt sonde tiểu. Theo Phùng Quang Thủy [4], bi tiểu chiếm 2,7\%. Chora I [5], trong nhóm Bupivacain kết hợp Fentanyl, không có trường hợp nào bí tiểu. Rất khó để đánh giá chính xác tỳ lệ bí tiểu do GTNMC để giảm đau trong chuyển dạ vì sản phụ thường được đặt sonde tiểu lưu hoặc có thể do giảm trương lực cơ bàng quang sau sinh.

- Ngứa: nghiên cứu gặp 0,6\%. sản phụ được tiêm kháng dị ứng Dimedrol $10 \mathrm{mg} /$ ống x 1 ống tiêm tĩnh mạch chậm, triệu chứng được cải thiện. Ngứa là tác dụng không mong muốn thường gặp nhất của Opioid dùng GTNMC hoặc tủy sống. Nguyên nhân ngứa chưa được biết đầy đủ nhưng ngứa không liên quan đến sự phóng thích histamin. Nghiên cứu của Chora I [5], ngứa chiếm $10 \%$.

- Đau đầu: chúng tôi gặp một trường hợp $(0,3 \%)$. Theo Phùng Quang Thủy [4] và Nguyễn Văn Chinh [1] tỷ lệ đau đâu lần lượt là $5,4 \%$ và $4,7 \%$. Trong nghiên cứu, tỷ lệ hài lòng là $66,87 \%$, đặc biệt tỷ lệ rất hài lòng là 30,68\%.

\section{KẾT LUÂNN}

Hiệu quả giảm đau trong chuyển dạ cho sản phụ sinh thường bằng thuốc Bupivacain và Fentanyl: Các giai đoạn của quá trình chuyển dạ, trước khi gây tê điểm VAS trung bình đều >7, sau khi khởi tê điểm VAS trung bình ở các giai đoạn của chuyển dạ đều $<4$.

Ghi nhận một số tác dụng không mong muốn nhưng khổng ảnh hưởng đên tổng trạng sản phụ trong cuộc đẻ như: lạnh run, tụt huyết áp, nôn, bí tiểu, ngứa, đau đầu.

\section{TÀI LIẸU THAM KHẢO}

1. Nguyễn Văn Chinh (2011), "Nghiên cứu gây tê ngoài màng cứng phối hợp Bupivacain với Fentanyl để giảm đau trong chưyển dạ", Tạp chí $Y$ học Thành phố Hồ Chí Minh, phụ bản số 3, tập 15, tr.186-194.

2. Đố Văn Lợi (2017), Nghiên cứu hiệu quả giảm đau trong chuyển dạ của phương pháp gây tê ngoài màng cứng bằng Bupivacain $0,1 \%$ phối hợp Fentanyl do và không do bệnh nhân tự điêu khiênn, Luận án Tiến sỹ Y học Đại học Y Hà Nội.

3. Nguyền Thị Thanh, Nguyến Trọng Thắng (2011), "Nghiên cứu hiệu quả và an toàn của giảm đau trong chuyển dạ với gây tê ngoài màng cứng bằng Bupivacain nồng độ thấp kết hợp Fentanyl không dùng liêu thứ", Tap chí $Y$ học Thành phổ Hồ Chí Minh, tập 15, phụ bản số 3, tr.101-108.

4. Phùng Quang Thủy, Cao Ngọc Thành (2012), "Nghiên cứu ứng dụng phương pháp đẻ không đau bằng gây tê ngoài màng cứng", Tạp chí Y học thực hành, số 12(854), tr.29-32.

5. Chora I., Hussain A. (2014), "Comparison of $0.1 \%$ Ropivacaine-Fentanyl with $0.1 \%$ BupivacainFentanyl Epidurally for Labour Analgesia", Advances in Anesthesiology.

6. Esra K., All K (2016), "Comparison of patient controlled analgesia with Bupivacain or Bupivacain plus Fentanyl during labor", International Journal of Clinical Anesthesiology. 4(2), pp.1-4.

7. Gündüz S., et al (2017), "Comparison of Bupivacain and Ropivacaine in combination with Fentanyl used for walking epidural anesthesia in labor", Turkish journal of obstetrics and gynecology. 14(3), pp.170.

8. Patkar C. S, et al (2015), "A comparison of continuous infusion and intermittent bolus administration of $0.1 \%$ Ropivacaine with $0.0002 \%$ Fentanyl for epidural labor analgesia", Journal of Anaesthesiology, Clinical Pharmacology. 31(2), pp.234. 